
\title{
ZS Research Suare \\ Analysis of the Psychological States of the Scientific Expeditioners in Extreme Environment
}

\author{
Jiayi Wang \\ Shanghai East Hospital \\ Haibin Li \\ Zhongshan Hospital \\ Lihong Qu \\ Shanghai East Hospital \\ Tao WANG \\ Shanghai East Hospital \\ Di GAN \\ Shanghai East Hospital \\ Ye Liu \\ Zhongshan Hospital \\ Wenjuan Liu \\ Zhongshan Hospital

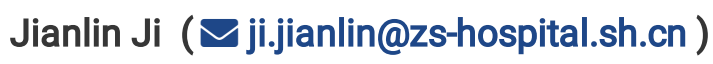 \\ Zhongshan Hospital
}

\section{Research Article}

Keywords: Arctic, Anxiety, Depression, Sleep, Personality

Posted Date: November 3rd, 2021

DOI: https://doi.org/10.21203/rs.3.rs-1023330/v1

License: (c) (i) This work is licensed under a Creative Commons Attribution 4.0 International License. Read Full License 


\section{Abstract}

Background: To investigate the relationship among individuals' mood, sleep and personality traits in a long-term polar environment.

Methods: A total of 85 Arctic expedition team members were recruited in this study. In addition to personality assessment, they also completed assessments of anxiety, depression, and sleep at baseline, the second and eighth week. The rank sum test was used to compare the differences between mood and sleep at different time periods, and the generalized linear mixed model was used to explore the relations between personality and mood, as well as sleep.

Results: The PHQ-9 scores showed a statistically significant difference between baseline and week 8. The PSQI scores showed a significant difference between baseline and week 2 . At the same time, there was a significant difference between those who are married and those being single. Single individuals scored significantly lower on GAD-7 than married ones. The relationship between personality traits and PHQ-9 scores was statistically significant and individuals' coping styles have an impact on their subjective sleep quality, sleep disturbance and daytime dysfunction.

Conclusion: In the polar environment, over time, people's mood and sleep will be affected, and that is related to individual characteristics, personality and coping styles.

\section{Introduction}

Human beings are curious about the unknown. With the development of science and technology, human beings have begun to challenge the polar regions. The polar environment is harsh, the climate is cold, the scenery of long-term maritime navigation is monotonous, faced with challenges such as difficulty in replenishment and many uncertainties. This is a huge challenge to the psychological state of the ship's crew members. Studies have shown that the polar environment can influence the cognition of researchers. For example, the time of decoding complex memories is prolonged, short-term memory and simple spatial cognition are improved in cold environments[1]. Studies have shown that the accuracy of recognition memory and learning ability has increased over time, while numerical short-term memory has not changed[2].

At the same time, the polar environment also has a huge impact on human emotions. A study about the Chinese expedition found that before and after the polar expedition, low levels of Triiodothyronine (T3), thyroxine (T4), high levels of thyrotropin stimulating hormone (TSH) and high levels of anxiety are related to high levels of anxiety , depression, anger and confusion. In addition, after living at the Great Wall Station for one year, the vitality of the individuals dropped significantly[3]. Motivation plays an important role in adapting to the external environment, selfcoordination and interpersonal relationships during the voyage. Using reasonable coping strategies is equally important for relieving stress, such as identifying problems, trying to solve the problems, staying focused, and maintaining an optimistic attitude[4]. Moreover, as the expedition time increases, the length of sleep time reduces, and these crew members become less active[5].

Countries all hope to select the most suitable persons to participate in the polar expeditions. Many countries will adopt various psychological assessments to reduce the risk of polar expeditions[6]. It is hoped that through the checkup, unsuitable persons can be eliminated[7]. Studies have shown that individuals with high emotional stability, conscientiousness, and high affinity have better adaptability, which is beneficial to working in Antarctica[8]. Due to the strict selection process, the emotional fluctuations of many members during their time in the Antarctic are homogenous[9]. 
However, most studies mainly focus on the Antarctic region, and there are few studies on the psychological state of people in the Arctic area. Arctic expeditions are very different from Antarctic expeditions. There is a large land area in Antarctica with multiple scientific research stations, while the Arctic has relatively few stations. Relative to the Antarctic, there are fewer expeditions. Although current research has explored the sleep, emotional changes, and cognitive functions of expedition members in polar regions, we still lack an in-depth understanding of this group of people. The purpose of this study is to gain insights into whether the sleep and personality traits of Arctic scientific expeditioners play a role in mood regulation, and the influence of time changes on emotions. We aim to further understand the time period during which obvious mood changes take place, and to provide guidance for subsequent psychological interventions.

\section{Methods}

\section{Participants}

Participants in the current study are members of China's 11th Arctic expedition (including crew members), with a total number of 85 persons. Their age ranged from $24-50$ years old, with an average age of $33.93 \pm 6.62$. All the participants completed the baseline assessment before departure, and the expedition started from July 15, 2020 to September 28, 2020.

\section{Measures}

\section{Depression Scale}

Patient Health Questionnaire-9 (PHQ-9) is part of the PHQ. PHQ-9 is a self-rating scale. There are 9 items in total, and each item ranged from 0 points (almost none) to 3 points (almost every day), four levels in total. Among them, if 5 or more items are rated as "More than half the days", and item 1 or 2 is rated as "More than half the days", it is considered as "Major Depressive Syndrome". If 2 to 4 items are at least rated as "More than half the days", and item 1 or item 2 is reported as "more than half of the days" at least, then it is considered as "Other Depressive Syndrome". A total score of 0 to 4 indicates no depression or at a minimal level. A total score of 5 to 9 indicates mild depression, 10 to 14 falls into the category of moderate depression, 15 to 19 indicates a level of moderate to severe depression, and 20 to 27 indicates severe depression. Studies have shown that a PHQ-9 score of 10 or higher has levels of $88 \%$ sensitivity and $88 \%$ specificity (Cronbach's a=0.89) [10].

\section{Anxiety Scale}

The Generalized Anxiety Disorder (GAD-7) is a self-rating scale with 7 items, ranging from 0 (nothing at all) to 3 (almost every day) with 4 levels. A score of 0 to 4 is considered to be no or mild anxiety, a score of 5 to 9 is considered as mild anxiety, a score of 10 to 14 is considered as moderate anxiety, and a score of 15 or more is considered severe. GAD-7 has good internal consistency, Cronbach's a coefficient is 0.92 , the test-retest reliability is 0.83 , and when the score is 10 , the sensitivity and specificity are both over 0.8[11]. GAD-7 also can be a good instrument to assess other anxiety spectrum disorders (such as panic attacks, social anxiety disorders, post-traumatic stress disorder, etc.)[12].

\section{Sleep assessment}

The Pittsburgh Sleep Quality Index (PSQI) was used to assess the sleep quality of the participants. It is a self-rating scale. The PSQI has 19 items, consisting of 7 components, with a total score of 0 to 21 points. The lower the score, the better the overall sleep quality is. The internal consistency of PSQI is relatively high, the Cronbach's a coefficient is 0.83. The Pearson correlation coefficient is 0.85 , indicating that it has good test-retest reliability. Compared with the 
Polysomnography, there are no significant differences between the two, and PSQI is better than the other in assessing the duration and efficiency of sleep in the past month[13].

\section{Personality test}

The Sixteen Personality Factor Questionnaire (16PF) was used as the personality test in this study. 16PF was developed by Cattel based on his personality theory. It has the following features: 1. Objectivity. The structure of 16PF is clear. There are neutral options so that participants are unlikely to be forced to choose an answer biased towards certain way. 2. Standardized. With good reliability, validity, and an average Cronbach's a coefficient of 0.63. 3. Generalizability. 16PF can be administered individually, as well as in group-settings. Fourth, profundity. The assessment results can be explained in conjunction with psychoanalytic theory.

\section{Coping style rating scale}

The Coping Style Questionnaire (CSQ) was developed by a group of Chinese researchers, led by Xiao, based on research from abroad, taking into consideration of the language characteristics and behavioral habits of people in China[14]. CSQ is composed of 6 factors, and its validity is 0.35 or higher for the factor loadings of each factor in the adolescent student group and neurosis-control group. At the same time, it has good reliability in both groups. According to the correlation, arranged in order in a diagram: avoidance, fantasy, self-blame, seek for help, rationalize, and solve the problem.

\section{Procedures}

The scientific expedition team members who undertake scientific research tasks completed 16PF and CSQ assessments before departure. All the participants completed PHQ-9, GAD-7 and PSQI before departure, at the $2^{\text {nd }}$ and $8^{\text {th }}$ week.

\section{Statistical analysis}

All data in this study was analyzed using SPSS 25. For the continuous variables obtained from PHQ-9, GAD-7 and PSQI, if the data was normally distributed, the paired $t$ test was used. Otherwise, the Wilcoxon Signed-Rank Test was used to explore the effects of the extreme environment on team members' emotions and sleep quality at different time periods. At the same time, participants were categorized into different groups based on their scores on the questionnaires mentioned above. In terms of scores on PHQ-9, those with a score of no more than 4 were in the asymptomatic group, those with 5 points and above were in the symptomatic group. For GAD-7, the cutoff was a score of 4 . The obtained a score no more than 4, and the symptomatic group got a score of 5 and above. Those with a PSQI score no more than 5 were in the asymptomatic group. For those who obtained a PSQI score of 6 and above, they were in the symptomatic group. Comparisons were made between different time periods and latitude, to see whether there are statistical differences among individuals in the symptomatic groups. In addition to investigating the changes of PHQ-9, GAD-7, and PSQI scores over time, this study conducted an open exploration of the relations among individual characteristics and coping styles, emotions, as well as sleep. A hybrid model was adopted to explore the relationships among various factors. We discard the missing data.

\section{Results}

\section{Demographic information}


A total of 79 people participated in this study, and some of the participants had missing data, missing data were discarded in the statistical analysis. Among them, there were 71 males and 3 females, and gender information of the other five persons was missing. Regarding marital status, the number of single persons is 23 , two individuals were divorced, 48 people were married. One person indicated "Other", and data was missing from five participants. A number of 15 participants lived alone, 16 participants reported to live with their parents, and seven individuals lived with their partners, two people live with children only. There were 31 participants living with partners and children, 8 people had missing data. In terms of levels of education, two people have middle school education and below. A number of eight people have high school education. There are 29 people who finished undergraduate. 35 individuals completed graduate studies and above, and data from five participants is missing.

At baseline, 73 participants experienced mild depression or none (PHQ-9 scores $\leq 9$ ), one person had moderate level of depression or above (PHQ-9 score $\geq 10$ ). Participants' GAD-7 scores indicated that 72 of them self-reported as experiencing mild anxiety or below (GAD scores $\leq 9$ ). Two people experienced moderate level of anxiety and above (GAD scores $\geq 10$ ). There were 62 people indicating acceptable sleep quality (PSQI scores $\leq 10$ ), and three people had poor sleep quality (PSQI scoreS $\geq 11$ ).

At the second week, 71 people experienced mild depression or none (PHQ-9 scores $\leq 9)$. One person had moderate level or above (PHQ-9 scores $\geq 10$ ). A number of 70 participants had GAD-7 scores indicating mild anxiety or below (GAD-7 scores $\leq 9$ ), and two people were moderate or above (GAD scores $\geq 10$ ). When it comes to sleep quality, 52 participants reported an acceptable level of sleep quality (PSQI scores $\leq 10$ ), and 7 people had poor sleep quality (PSQI scores $\geq 11$ ).

At the 8th week, 65 people reported to have mild depression or none (PHQ-9 scores $\leq 9$ ), 2 had moderate level or above (PHQ-9 scores $\geq 10$ ). GAD-7 scores showed that 64 people experienced mild anxiety or below (GAD-7 scores $\leq 9$ ) , two people had moderate anxiety or above (GAD scores $\geq 10$ ). Regarding sleep quality, a total of 55 people reported to have acceptable sleep quality (score $\leq 10$ ), and five people had poor sleep quality (score $\geq 11$ ).

\section{Relationship between time, the latitude and GAD-7, PHQ-9, PSQI}

In this scientific expedition itinerary, the latitude and longitude were recorded once every 6 hours. The average latitude during the first week was $41.03^{\circ} \pm 6.59^{\circ}$, the average latitude during the second week was $60.33^{\circ} \pm 6.72^{\circ}$, and the average latitude during the eighth week was $76.42^{\circ} \pm 1.21^{\circ}$. Over time, the latitude at which the scientific expedition team arrived continued to increase. The distribution of GAD-7, PHQ-9, and PSQI scores is not normally distributed. Therefore, Wilcoxon signed-rank test was used. There were no statistically significant differences in GAD-7 scores between different time period (baseline, week 2 and week 8). The There was a statistically significant difference in PHQ-9 scores between baseline and the $8^{\text {th }}$ week. At baseline, the median of PHQ-9 scores was 2 and that at week 8 was 3 . Wilcoxon signed-rank test showed that $Z=-2.768, P<0.05$. However, there were no statistically significant differences between baseline and the $2^{\text {nd }}$ week, the $2^{\text {nd }}$ and the $8^{\text {th }}$ week in PHQ-9 scores. The PSQI scores showed a statistical difference between baseline and the $2^{\text {nd }}$ week. The median score of PSQI at baseline was 5 and the median at the $2^{\text {nd }}$ week was 5 . Wilcoxon signed-rank test showed that $Z=-2.104, P<0.05$. However, there were no statistically significant differences in PSQI scores between baseline and the $8^{\text {th }}$ week, the $2^{\text {nd }}$ week and the $8^{\text {th }}$ week.

This study also explored the PSQI subscales, and found that statistical differences existed in sleep latency between baseline and the $2^{\text {nd }}$ week, the $2^{\text {nd }}$ and the $8^{\text {th }}$ week, $Z=-3.748, Z=-2.436$ respectively. There were statistical differences in sleep duration between baseline and the $2^{\text {nd }}$ week, baseline and the $8^{\text {th }}$ week, and between the $2^{\text {nd }}$ and $8^{\text {th }}$ week, 
$Z=-2.179, Z=-2.745, Z=-3.947$ respectively. Statistical differences in daytime dysfunction existed only between baseline and the $8^{\text {th }}$ week, $Z=-2.408$ (Figure 1).

\section{Relationship between time, latitude and different symptomatic groups of PHQ-9, GAD-7, PSQI}

Cochran's Q test was used to explore the similarities and differences among different symptomatic groups of PHQ-9, GAD-7 and PSQI at different time and latitudes. The results showed that based on PHQ-9 scores, a total of 62 participants were included. The percentages of the symptomatic group at baseline, the $2^{\text {nd }}$ and $8^{\text {th }}$ week were $25.8 \%$, $30.6 \%$, and $37.1 \%$, respectively, $\chi 2=5.286, p=0.071>0.05$. There were no significant differences at these three time points for the symptomatic group. Based on scores on GAD-7, a total of 61 participants were included. The proportions of the symptomatic group at baseline, the $2^{\text {nd }}$ and $8^{\text {th }}$ week were $14.8 \%, 21.3 \%$, and $19.7 \%$, respectively, $\chi 2=1.733, p=0.42>0.05$. There were no significant differences at these three time points for the symptomatic group. Based on PSQI scores, 43 people were included. The proportions of the symptomatic group at baseline, the $2^{\text {nd }}$ and $8^{\text {th }}$ week were $34.9 \%, 37.2 \%$, and $44.2 \%$, respectively, $\chi 2=2, p=0.368>0.05$. There were no significant differences at these three time points for the symptomatic group (Figure 2).

\section{Personal characteristics and emotional changes in the polar environment}

\section{Relationship between personal background information and PHQ-9, GAD-7, PSQI and its subscales}

This study also explored the influence of personality traits on mood and sleep conditions, and investigated whether different individual characteristics play a role in changes in mood and sleep. A total of 29 people completed the relevant assessments, and the missing data were discarded. This study applied a generalized linear mixed model to analyze data from repeated measures. The following factors were taken into consideration: age, marital status, level of education, current living conditions, personality traits, and coping styles.

The results indicated that the model exploring relations between PHQ-9 scores and personal background information such as age, marital status, education level, personal income and current living conditions etc., was not statistically significant. The relation between marital status and GAD-7 scores was statistically significant $(F=5.065, p<0.05)$. Specifically, singleness was associated with lower scores on GAD-7. Personal conditions and the PSQI total Scores were not related in a statistically significant way, instead were related to the subscales of PSQI significantly, including sleep quality, sleep latency, sleep duration, and sleep efficiency (Table 1, Table 2). Pairwise comparison indicated that compared with individuals with income $>10,000$ RMB per capita, those with an income of 5,000-10,000 RMB per capita had worse sleep quality. (coefficient 0.52 , $p<0.05$ ). In terms of sleep latency, compared with individuals having an income $>10,000$ RMB and a graduate degree or above, those with an income of 5,000-10,000 RMB per capita (coefficient 1.002, $p<0.05$ ), and a bachelor degree (coefficient $0.75, p<0.05$ ) had longer sleep latency while those with a high school education (coefficient $-0.87, p<0.05$ ) had shorter sleep latency. With the increase of age (coefficient 0.04 , $p<0.01$ ), the total sleep duration decreases gradually. Those with an undergraduate degree (coefficient $0.38, p<0.03$ ) had shorter duration of sleep time compared with participants with high school education (coefficient $-0.54, p<0.05$ ). In terms of sleep efficiency, with the increase in age (coefficient $-0.07, p<0.05$ ), sleep efficiency improved. People living alone (coefficient -1.71, $p<0.05$ ), living with parents (coefficient -1.84, $p<0.05$ ) experienced better sleep efficiency than those living with partners and children. People who had an income <5000 RMB (coefficient $-0.94, p<0.05$ ) and those with an income between 5000-10000 RMB (coefficient -0.77, $p<0.05$ ) had better sleep efficiency than individuals having an income greater than 10,000 RMB.

Table 1 The influence of personal background information on PHQ-9, GAD-7, PSQI 


\begin{tabular}{|lllllll|}
\hline & PHQ-9 & \multicolumn{3}{l}{ GAD-7 } & PSQI \\
\cline { 2 - 8 } & $\mathrm{F}$ & $\mathrm{p}$ & $\mathrm{F}$ & $\mathrm{p}$ & $\mathrm{F}$ & $\mathrm{p}$ \\
\hline Calibration model & 1.11 & 0.37 & 1.91 & 0.07 & 1.17 & 0.33 \\
\hline Age & 0.91 & 0.34 & 1.78 & 0.19 & 1.26 & 0.27 \\
\hline Marital status & 0.75 & 0.39 & 5.07 & $0.03^{*}$ & 0.00 & 0.98 \\
\hline Living conditions & 0.23 & 0.88 & 0.68 & 0.57 & 0.68 & 0.57 \\
\hline Salary & 0.43 & 0.65 & 0.34 & 0.72 & 2.69 & 0.08 \\
\hline Education & 1.77 & 0.18 & 1.76 & 0.18 & 0.46 & 0.64 \\
\hline
\end{tabular}

${ }^{*} \mathrm{p}<0.05$

Table 2 The influence of personal background information on PSQI subscales

\begin{tabular}{|c|c|c|c|c|c|c|c|c|c|c|c|c|}
\hline & \multicolumn{2}{|c|}{ sleep quality } & \multicolumn{2}{|c|}{ sleep latency } & \multicolumn{2}{|c|}{$\begin{array}{l}\text { sleep } \\
\text { duratio-n }\end{array}$} & \multicolumn{2}{|c|}{$\begin{array}{l}\text { sleep } \\
\text { efficien-cy }\end{array}$} & \multicolumn{2}{|c|}{$\begin{array}{l}\text { sleep } \\
\text { disturba- } \\
\text { nce }\end{array}$} & \multicolumn{2}{|c|}{$\begin{array}{l}\text { daytime } \\
\text { dysfuncti-on }\end{array}$} \\
\hline & $\mathrm{F}$ & $\mathrm{p}$ & $\mathrm{F}$ & $\mathrm{p}$ & $\mathrm{F}$ & $\mathrm{p}$ & $\mathrm{F}$ & $\mathrm{p}$ & $\mathrm{F}$ & $\mathrm{p}$ & $\mathrm{F}$ & $\mathrm{p}$ \\
\hline $\begin{array}{l}\text { Calibra-tion } \\
\text { model }\end{array}$ & 1.24 & 0.28 & 4.78 & $0.00^{*}$ & 3.83 & $0.00^{*}$ & 1.95 & 0.06 & 1.14 & 0.35 & 2.01 & 0.05 \\
\hline Age & 0.00 & 0.96 & 0.84 & 0.36 & 7.08 & $0.01^{*}$ & 8.62 & $0.00^{*}$ & 0.20 & 0.66 & 1.94 & 0.17 \\
\hline Marital status & 0.30 & 0.59 & 0.00 & 0.99 & 2.29 & 0.14 & 3.42 & 0.07 & 0.05 & 0.82 & 0.52 & 0.47 \\
\hline $\begin{array}{l}\text { Living } \\
\text { conditio-ns }\end{array}$ & 0.16 & 0.93 & 0.240 & 0.87 & 1.78 & 0.16 & 2.91 & $0.04^{*}$ & 1.31 & 0.28 & 2.07 & 0.11 \\
\hline Salary & 4.59 & $0.01^{*}$ & 15.41 & $0.00^{*}$ & 1.90 & 0.16 & 3.44 & $0.04^{*}$ & 1.11 & 0.34 & 0.03 & 0.97 \\
\hline Educatio-n & 1.64 & 0.20 & 6.97 & $0.00^{*}$ & 5.88 & $0.00^{*}$ & 1.38 & 0.26 & 1.56 & 0.22 & 2.48 & 0.09 \\
\hline
\end{tabular}

${ }^{*} \mathrm{p}<0.05$

\section{Relationships between personality traits and PHQ-9, GAD-7, PSQI and its subscales}

The model of personality traits and PHQ-9 scores is of statistical significance $(F=2.18, p<0.05)$. The higher the score of Factor Q4 Tension (coefficient of 0.59, p<0.05), the higher the score of PHQ-9 is. Personality traits are related to GAD-7 scores in a statistically significant way $(F=3.40, p<0.05)$. Higher scores of Factor A Warmth (coefficient -0.27 , $\mathrm{p}<0.05$ ), and Factor $E$ Dominance (coefficient $-0.24, p<0.05$ ) are correlated with lower scores on GAD-7. Scores of Factor $\mathrm{F}$ Liveliness (coefficient $0.43, \mathrm{p} \otimes 0.05$ ), factor M Abstractedness (coefficient $0.20, \mathrm{p} \otimes 0.04$ ), and Factor $\mathrm{N}$ Privateness (coefficient $0.21, \mathrm{p} \otimes 0.03$ ) are positively correlated with GAD-7 scores. The model based on the relations between personality traits and PSQI scores is of statistical significance $(F=3.55, p<0.05)$. Factor $L$ Vigilance (coefficient $-0.38, \mathrm{p}<0.05$ ) is negatively correlated with PSQI score, Factor M Abstractedness (coefficient $0.41, \mathrm{p}<0.05$ ), Factor Q3 Perfectionism (coefficient 0.723, $p<0.05$ ), and Factor Q4 Tension (coefficient 1.19, $p<0.05$ ) are positively correlated with PSQI scores (Table 3). 
Table 3 The influence of personality traits on PHQ-9, GAD-7, PSQI

\begin{tabular}{|lllllll|}
\hline & PHQ-9 & \multicolumn{3}{ll}{ GAD-7 } & PSQI \\
\cline { 2 - 7 } & $\mathrm{F}$ & $\mathrm{p}$ & $\mathrm{F}$ & $\mathrm{p}$ & $\mathrm{F}$ & $\mathrm{p}$ \\
\hline Calibration model & 2.18 & $0.02^{*}$ & 3.40 & $0.00^{*}$ & 3.55 & $0.00^{*}$ \\
\hline $\mathrm{a}$ & 0.01 & 0.94 & 6.42 & $0.01^{*}$ & 0.05 & 0.82 \\
\hline $\mathrm{b}$ & 0.28 & 0.60 & 1.80 & 0.18 & 0.07 & 0.79 \\
\hline $\mathrm{c}$ & 0.78 & 0.38 & 2.72 & 0.10 & 0.34 & 0.56 \\
\hline e & 0.12 & 0.73 & 7.05 & $0.01^{*}$ & 1.78 & 0.19 \\
\hline $\mathrm{f}$ & 2.13 & 0.15 & 15.14 & $0.00^{*}$ & 1.06 & 0.31 \\
\hline $\mathrm{g}$ & 0.00 & 0.99 & 0.79 & 0.38 & 0.94 & 0.34 \\
\hline $\mathrm{h}$ & 2.17 & 0.15 & 1.29 & 0.26 & 0.02 & 0.90 \\
\hline i & 0.37 & 0.55 & 0.09 & 0.76 & 0.11 & 0.75 \\
\hline $\mathrm{I}$ & 0.10 & 0.55 & 3.37 & 0.07 & 4.85 & $0.03^{*}$ \\
\hline $\mathrm{m}$ & 2.04 & 0.16 & 4.23 & $0.04^{*}$ & 6.26 & $0.02^{*}$ \\
\hline $\mathrm{n}$ & 0.57 & 0.45 & 5.06 & $0.03^{*}$ & 1.10 & 0.30 \\
\hline o & 0.01 & 0.91 & 2.18 & 0.15 & 0.01 & 0.92 \\
\hline Q1 & 3.96 & 0.05 & 1.87 & 0.18 & 1.91 & 0.17 \\
\hline Q2 & 0.21 & 0.65 & 2.67 & 0.11 & 0.02 & 0.89 \\
\hline Q3 & 0.05 & 0.83 & 0.76 & 0.39 & 6.95 & $0.01^{*}$ \\
\hline Q4 & 5.18 & $0.03^{*}$ & 0.90 & 0.35 & 19.57 & $0.00^{*}$ \\
\hline
\end{tabular}

${ }^{*} \mathrm{p}<0.05$

This study also explored the relationships between personality traits and the PSQI subscale. It was found that different personality traits have an impact on multiple subscales, including sleep quality, sleep latency, sleep duration, sleep efficiency, and sleep disturbances (Table 4). Factor Q4 Tension (coefficient 0.21, $p<0.05$ ) score is positively correlated with sleep quality score. Factor L Vigilance (coefficient $-0.15, p<0.05$ ), Factor N Privateness (coefficient $-0.12, p<0.05$ ) score and sleep latency score is negatively correlated. Factor M Abstractedness (coefficient $0.06, p \rrbracket$

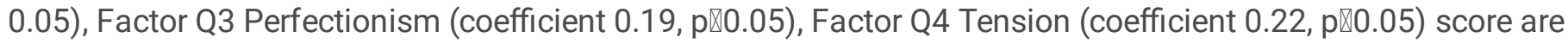
positively correlated with sleep duration score. However, the scores of the following factors are negatively correlated with sleep duration, including Factor B Reasoning (coefficient $-0.09, \mathrm{p}<0.05$ ), Factor C Emotional Stability (coefficient $-0.07, p<0.05$ ), Factor $F$ Liveliness (coefficient $-0.08, p<0.05$ ), Factor I Sensitivity (coefficient $-0.09, p<0.05$ ), Factor 0 Apprehension (coefficient $-0.12, p<0.05$ ), and Factor Q1 Openness to Change (coefficient $-0.07, p<0.05$ ). The scores of the following factors are positively related to sleep efficiency scores, Factor B Reasoning (coefficient $0.18, p<0.05$ ), Factor F Liveliness (coefficient 0.20, $p<0.05$ ), Factor M Abstractedness (coefficient $0.16, p<0.05$ ), Factor $N$ Privateness 
(coefficient 0.09, p<0.05), Factor Q1 Openness to Change (coefficient 0.12, p囚0.05), Factor Q3 Perfectionism

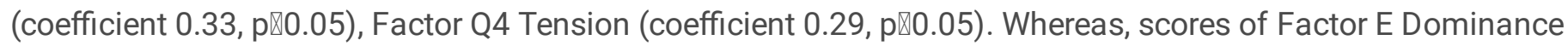
(coefficient -0.17) , P凶0.05), and Factor L Vigilance (coefficient $-0.13, \mathrm{p} \otimes 0.05$ ) are negatively correlated with sleep efficiency scores. Scores of the following factors are positively related to scores on the sleep disturbance subscale, Factor F Liveliness (coefficient 0.08, p囚0.05), Factor M Abstractedness (coefficient 0.09, p凶0.05) 0.05), Factor N Privateness (coefficient 0.07, p<0.05), Factor Q2 Self-Reliance (coefficient 0.07, $p<0.05$ ). Whereas scores of Factor $A$ Warmth (coefficient $-0.08, p<0.05$ ) ), Factor B Reasoning (coefficient -0.12, p<0.05), Factor E Dominance (coefficient $-0.07, p<0.05$ ), Factor I Sensitivity (coefficient $-0.08, p<0.05$ ) are negative correlated with sleep disturbance scores.

Table 4 The influence of personality traits on PSQI subscales

\begin{tabular}{|c|c|c|c|c|c|c|c|c|c|c|c|c|}
\hline & \multicolumn{2}{|c|}{ sleep quality } & \multicolumn{2}{|c|}{$\begin{array}{l}\text { sleep } \\
\text { latency }\end{array}$} & \multicolumn{2}{|c|}{ sleep duration } & \multicolumn{2}{|c|}{$\begin{array}{l}\text { sleep efficienc- } \\
y\end{array}$} & \multicolumn{2}{|c|}{$\begin{array}{l}\text { sleep } \\
\text { disturba-nce }\end{array}$} & \multicolumn{2}{|c|}{$\begin{array}{l}\text { daytime } \\
\text { dysfunct-ion }\end{array}$} \\
\hline & $\mathrm{F}$ & $\mathrm{p}$ & $\mathrm{F}$ & $\mathrm{p}$ & $\mathrm{F}$ & $\mathrm{p}$ & $\mathrm{F}$ & $\mathrm{p}$ & $\mathrm{F}$ & $\mathrm{p}$ & $\mathrm{F}$ & $\mathrm{p}$ \\
\hline $\begin{array}{l}\text { Calibra- } \\
\text { tion } \\
\text { model }\end{array}$ & 2.08 & $0.02^{*}$ & 3.37 & $0.00^{*}$ & 3.58 & $0.00^{*}$ & 5.35 & $0.00^{*}$ & 4.12 & $0.00^{*}$ & 3.52 & 0.00 \\
\hline a & 0.60 & 0.44 & 2.27 & 0.14 & 0.06 & 0.81 & 2.62 & 0.11 & 8.93 & $0.00^{*}$ & 0.01 & 0.93 \\
\hline$b$ & 2.79 & 0.10 & 0.93 & 0.34 & 4.68 & $0.03^{*}$ & 8.54 & $0.01^{*}$ & 14.14 & $0.00^{*}$ & 4.20 & 0.045 \\
\hline C & 0.14 & 0.71 & 0.20 & 0.65 & 4.20 & $0.045^{*}$ & 0.87 & 0.35 & 0.61 & 0.44 & 7.24 & 0.01 \\
\hline e & 0.01 & 0.92 & 0.02 & 0.89 & 1.52 & 0.22 & 14.99 & $0.00^{*}$ & 11.89 & $0.00^{*}$ & 0.66 & 0.42 \\
\hline$f$ & 0.49 & 0.49 & 0.47 & 0.50 & 5.26 & $0.03^{*}$ & 12.32 & $0.00^{*}$ & 8.90 & $0.00^{*}$ & 0.59 & 0.45 \\
\hline$g$ & 0.61 & 0.44 & 0.84 & 0.36 & 0.17 & 0.68 & 0.69 & 0.41 & 3.39 & 0.07 & 1.46 & 0.23 \\
\hline $\mathrm{h}$ & 0.28 & 0.60 & 1.01 & 0.32 & 0.28 & 0.60 & 1.50 & 0.23 & 2.02 & 0.16 & 1.51 & 0.22 \\
\hline i & 1.67 & 0.20 & 3.26 & 0.08 & 8.27 & $0.01^{*}$ & 0.24 & 0.63 & 0.94 & 0.34 & 0.50 & 0.48 \\
\hline I & 0.45 & 0.51 & 5.75 & $0.02^{*}$ & 0.82 & 0.37 & 6.04 & $0.02^{*}$ & 8.48 & $0.01^{*}$ & 0.93 & 0.34 \\
\hline $\mathrm{m}$ & 0.00 & 0.98 & 1.73 & 0.19 & 4.04 & $0.049^{*}$ & 10.28 & $0.00^{*}$ & 14.26 & $0.00^{*}$ & 0.32 & 0.58 \\
\hline $\mathrm{n}$ & 0.00 & 0.98 & 4.71 & $0.03^{*}$ & 1.41 & 0.24 & 4.19 & $0.045^{*}$ & 10.70 & $0.00^{*}$ & 5.91 & 0.02 \\
\hline 0 & 0.00 & 0.97 & 1.98 & 0.16 & 6.81 & $0.01^{*}$ & 0.38 & 0.54 & 0.15 & 0.70 & 0.52 & 0.47 \\
\hline Q1 & 0.13 & 0.73 & 0.01 & 0.92 & 4.94 & $0.03^{*}$ & 7.17 & $0.01^{*}$ & 2.42 & 0.13 & 10.57 & 0.00 \\
\hline Q2 & 1.76 & 0.19 & 0.76 & 0.39 & 3.71 & 0.06 & 0.05 & 0.83 & 6.50 & $0.01^{*}$ & 0.01 & 0.93 \\
\hline Q3 & 1.90 & 0.17 & 0.31 & 0.58 & 12.70 & $0.00^{*}$ & 15.45 & $0.00^{*}$ & 0.59 & 0.44 & 0.61 & 0.44 \\
\hline Q4 & 8.10 & $0.01^{*}$ & 2.24 & 0.14 & 15.23 & $0.00^{*}$ & 12.14 & $0.00^{*}$ & 0.01 & 0.92 & 9.79 & 0.00 \\
\hline
\end{tabular}

${ }^{*} p<0.05$ 
The relations between coping styles and PHQ-9, GAD-7 and PSQI scores have statistical significance (Table 5). Further analysis showed that coping styles have an impact on sleep quality, sleep disturbances and daytime dysfunction. The help-seeking factor (coefficient $0.91, p<0.05$ ) is positively correlated with the sleep quality score; the problem-solving factor (coefficient $-1.46, p<0.05$ ) is negatively correlated with the sleep disturbance score, and the help-seeking factor (coefficient $0.77, p<0.05$ ) is positively correlated with the score of sleep disturbance. The selfblaming factor (coefficient $3.08, p<0.05$ ) is positively correlated with the daytime dysfunction score (Table 6).

Table 5 The influence of coping styles on PHQ-9, GAD-7, PSQI

\begin{tabular}{|lllllll|}
\hline & PHQ-9 & \multicolumn{3}{c}{ GAD-7 } & PSQI \\
\cline { 2 - 7 } & $\mathrm{F}$ & $\mathrm{p}$ & $\mathrm{F}$ & $\mathrm{p}$ & $\mathrm{F}$ & $\mathrm{p}$ \\
\hline Calibration model & 2.86 & $0.02^{*}$ & 3.13 & $0.01^{*}$ & 2.46 & $0.03^{*}$ \\
\hline Problem-solving & 1.44 & 0.23 & 0.03 & 0.87 & 0.70 & 0.41 \\
\hline Self-blaming & 0.97 & 0.33 & 1.35 & 0.25 & 1.71 & 0.20 \\
\hline Help-seeking & 0.07 & 0.79 & 1.22 & 0.27 & 1.05 & 0.31 \\
\hline Fantasy & 0.65 & 0.42 & 0.30 & 0.59 & 0.03 & 0.87 \\
\hline Withdrawing & 1.04 & 0.31 & 3.52 & 0.07 & 2.21 & 0.14 \\
\hline Rationalization & 0.63 & 0.43 & 0.98 & 0.33 & 0.05 & 0.83 \\
\hline
\end{tabular}

${ }^{*} \mathrm{p}<0.05$

Table 6 The influence of coping styles on PSQI subscales

\begin{tabular}{|c|c|c|c|c|c|c|c|c|c|c|c|c|}
\hline & \multicolumn{2}{|c|}{ sleep quality } & \multicolumn{2}{|c|}{$\begin{array}{l}\text { sleep } \\
\text { latency }\end{array}$} & \multicolumn{2}{|c|}{$\begin{array}{l}\text { sleep } \\
\text { duration }\end{array}$} & \multicolumn{2}{|c|}{$\begin{array}{l}\text { sleep } \\
\text { efficienc-y }\end{array}$} & \multicolumn{2}{|c|}{$\begin{array}{l}\text { sleep } \\
\text { disturbanc-e }\end{array}$} & \multicolumn{2}{|c|}{$\begin{array}{l}\text { daytime } \\
\text { dysfunctio-n }\end{array}$} \\
\hline & $\mathrm{F}$ & $\mathrm{p}$ & $\mathrm{F}$ & $\mathrm{p}$ & $\mathrm{F}$ & $\mathrm{p}$ & $\mathrm{F}$ & $\mathrm{p}$ & $\mathrm{F}$ & $\mathrm{p}$ & $\mathrm{F}$ & $\mathrm{p}$ \\
\hline $\begin{array}{l}\text { Calibration } \\
\text { model }\end{array}$ & 2.84 & $0.02^{*}$ & 1.81 & 0.11 & 0.29 & 0.94 & 0.63 & 0.71 & 2.97 & $0.01^{*}$ & 5.59 & $0.00^{*}$ \\
\hline $\begin{array}{l}\text { Problem- } \\
\text { solving }\end{array}$ & 1.44 & 0.24 & 3.28 & 0.08 & 0.63 & 0.43 & 0.40 & 0.53 & 7.50 & $0.01^{*}$ & 0.11 & 0.74 \\
\hline Self-blaming & 3.01 & 0.09 & 0.83 & 0.37 & 0.10 & 0.75 & 0.31 & 0.58 & 0.72 & 0.40 & 8.44 & $0.01^{*}$ \\
\hline Help-seeking & 4.68 & $0.03^{*}$ & 1.66 & 0.20 & 0.13 & 0.72 & 0.03 & 0.87 & 6.56 & $0.01^{*}$ & 0.26 & 0.61 \\
\hline Fantasy & 0.34 & 0.56 & 0.00 & 0.94 & 0.00 & 1.00 & 1.24 & 0.27 & 0.42 & 0.52 & 3.51 & 0.07 \\
\hline Withdrawing & 2.84 & 0.10 & 0.15 & 0.70 & 0.99 & 0.32 & 3.54 & 0.06 & 1.94 & 0.17 & 1.51 & 0.22 \\
\hline Rationalization & 0.33 & 0.57 & 2.19 & 0.14 & 0.04 & 0.85 & 0.36 & 0.55 & 1.71 & 0.20 & 0.46 & 0.50 \\
\hline
\end{tabular}

${ }^{*} \mathrm{p}<0.05$

\section{Discussion}




\section{Changes in levels of anxiety, depression and sleep condition in polar environments}

It was found in the study that with the extension of polar time, the expedition members' level of depression increased, and the anxiety symptoms did not change significantly at every time of evaluation. This is similar to previous studies. Moraes and colleagues conducted a 50-day study regarding Antarctic expedition and found that the emotional states of the team members changed significantly as the time on board increased, manifested by decreased vitality, increases in depression and the average score of negative dimensions. There were no obvious changes in other dimensions[15]. Mairesse monitored the sleep condition of Antarctic expeditioners using Polysomnography and selfrating scales, starting from 2-3 months after they arrived at the station. The Polysomnography showed that the overall sleep quality and various dimensions of the team members remained stable, while the sleep latency was extended. The self-rating scale showed the same results[16]. This is consistent with the conclusions of this study, there were no significant differences in sleep assessment results between the 2nd and 8th week. Furthermore, it was found that there is a difference in sleep condition between the baseline and the second week, which may be caused by the obvious changes in the sleep environment initially. With the adaptation to the environment, the sleep condition gradually went back to normal. Sleep latency at the second week was longer than that at the baseline.

Many studies have shown that the prevalence of depression is higher at higher latitudes, and migration from low latitudes to high latitudes can increase the prevalence of depression[17-19]. Meanwhile, years of residence may be negatively correlated with the prevalence of depression[20]. These studies suggest that higher latitudes population is more likely to suffer from depression than lower latitudes population. However, as years of residence becomes longer, their depression situation decrease. The prevalence of depression in people newly moved to higher latitudes will increase, and subsequently decrease gradually. In these studies, the influence of the latitude on people's mood is longterm, usually counted in years, and the short-term effect may not be obvious. Moreover, latitude may only be an intermediate variable, because high latitudes will bring risks such as reduced daylight hours, which are risk factors for depression originally. Many studies have found that lack of sunlight can increase the risk of depression[21, 22], and a lack of sunlight can lead to vitamin D deficiency, which is also considered to be closely related to depression[23]. Vitamin D supplementation can relieve depressive symptoms[24]. A meta-analysis showed that light with an intensity of $\geq 5000$ lux for no less than 30 minutes is effective for improving condition of depression[25].

\section{The influence of personal background information, personality traits and coping styles on anxiety, depression and sleep}

Personality is a unique integration pattern that constitutes a person's thoughts, emotions, and behaviors. This unique pattern contains a stable and unified mental trait that distinguishes an individual from others[26]. Its formation has both innate factors and influence from the environment. Everyone's personality is unique and stable, so everyone responds to the same environment differently but stably, which is predictable to a certain degree. Having a good, wholesome personality and mature coping styles are necessary for individuals to deal with harsh environments.

This study showed that team members' depressive symptoms became severe over time and had no apparent relationship with the team members' personal background information and coping styles. Personality tests indicate that people with high level of tension and neuroticism are more likely to experience depression. The results suggest that time spent in the polar environment may be an independent risk factor for depressed mood. It is necessary to pay attention to the mental health of expedition team members who stay in polar region in a long-term, to intervene in a timely manner.

Studies have found that being single can reduce overall level of anxiety. There are also inconsistencies in previous research, Adamczyk et al.[27] believe that it is incorrect for the society to associate being single with negative 
stereotypes such as feeling miserable, insecure, and dissatisfied with life[28]. Especially for people who are willing to be single, being single is an expression of individuality and personal attitude[29]. On the other hand, Vivian et al.[30] believe that married people can expand shared social networks, share and buffer stress with their partners, while single persons may participate in more social activities due to social pressures and other reasons. Meanwhile, single persons are prone to experience stress related to loneliness, which in turn are more likely to bring about anxiety. Previous studies on the relationship between singleness and anxiety were conducted in a normal social environment. However, the current study was conducted in an enclosed and isolated environment, there are differences between these two. The authors of the study believe that compared with married team members, single team members do not have a commitment to their partners, and have less responsibility for the family. This instead become an advantage for them in the enclosed and isolated polar environment. Besides, for married people, the pattern of sharing stress with partners is not applicable in the polar regions. Instead, they adapted to the environment slowly and experienced increased level of anxiety. Research indicates that people who are enthusiastic, outgoing, and unorthodox tend to have lower levels of anxiety, while people who are easily excited, full of fantasy, and well-versed are more likely to be anxious. This has been supported by other studies, high affinity, frankness, and introverted persons are prone to experience more distress when faced with interpersonal stressors[31, 32]. It is worth noting that a study concerning high altitude regions showed that factor $M$ (Abstractedness) is negatively correlated with anxiety state[33]. This suggests that personality traits are still inconsistent in research of anxiety levels in extreme environments.

Generally speaking, middle-income (5000-10000 RMB), undergraduate degree, increase in age, and living with partners and children are prone to have adverse effects on sleep. A meta-analysis showed that about $6.8 \%$ of adults sleep less than 6 hours, and this proportion expands to 25\% with the increase in age[34]. Ohayon et al. found that as people become older, their total sleep time, sleep efficiency, slow-wave sleep, rapid eye movement (REM) sleep and REM latency decrease[35]. Not only that, how is the family environment, whether it is crowded also influence sleep[36]. The sleep quality of individuals who live with their partners and children is worse than that of people who live alone or with their parents. This may due to the fact that persons have the responsibility for taking care of their partners and children when living with them. There is no need to think about taking care of families when living alone. When living with the parents, individuals are often the ones being taken care of, so they sleep well. Some studies indicate that high income is beneficial for sleep, but considering other benefits brought by high income (such as better education, medical care, and the environment), high income will affect sleep[36]. Therefore, high income does not bring about a good sleep directly. However, it can improve other factors that influence sleep. We found that middleincome team members sleep worse than higher-income ( $>10,000 \mathrm{RMB})$ and low-income $(<5000 \mathrm{RMB})$ team members. This was not completely in line with the finding that high-income can improve sleep quality. This may be related to the possibility that middle-income team members have more pursuits in life and it can be difficult for them to achieve. Furthermore, personality also has an impact on sleep. For example, people with high scores on factor Q4 (Tension) have worse sleep quality. These people have characteristics such as nervousness and neuroticism, which are consistent with other research findings[37]. Suspicious and alert people fall asleep faster, have higher sleep efficiency, and sleep better, and so on. Different ways of coping with problems can also affect sleep. Those with high scores on factor of problem-solving are less likely to experience sleep disturbances, whereas the factors of help-seeking and self-blaming have a negative impact on sleep. These results indicate that if a person adopts a more mature way of dealing with incidents, and his personality is relatively stable, then his sleep quality may be better.

\section{Conclusion}

We found that depressive symptoms can change over time, and in the early two weeks, the quality of sleep decreased. Different personal background, personality and coping styles also influenced mood and sleep to some extent.

Page $12 / 17$ 


\section{Limitations}

In this study, because there were no professional psychiatrists on board, the anxiety and depression scales were selfrated, the validity of the assessment was affected. At the same time, the ocean waves brought disturbances to some people during their sleep. Also, we were unable to monitor participants' sleep condition using Polysomnography, and the analysis of sleep condition cannot be combined with objective data. Although this study found that both personality traits and coping styles have an impact on mood and sleep, the results should be interpreted with caution. Continuous research concerning expedition team members on a large-scale is needed.

\section{Declarations}

\section{Ethics approval}

The study was approved by the Ethics committee of Zhongshan Hospital Fudan University, China. (IRB No. B2020204R).

\section{Availability of data and materials}

The datasets used and/or analysed during the current study are available from the corresponding author on reasonable request.

\section{Competing interests}

The authors declare that they have no competing interests.

\section{Authors' contributions}

TW, WL and JJ participated in the design of the study. JW carried out data collection. $\mathrm{HL}$ and YL performed the statistical analysis and participated in the coordination of the study. WJ, HL, LQ, TW and DG drafted the manuscript and revised the manuscript. WL and JJ provided critical revision of the manuscript for important intellectual content.

\section{Funding}

Not applicable.

\section{Consent for Publication}

All the authors agree to publish.

\section{Acknowledgements}

Not applicable.

\section{References}

1. Reed HL, Reedy KR, Palinkas LA, Van Do N, Finney NS, Case HS, LeMar HJ, Wright J, Thomas J: Impairment in cognitive and exercise performance during prolonged antarctic residence: effect of thyroxine supplementation in the polar triiodothyronine syndrome. The Journal of Clinical Endocrinology \& Metabolism 2001, 86(1):110-116.

2. Paul FJ, Mandal MK, Ramachandran K, Panwar MR: Cognitive performance during long-term residence in a polar environment. J ENVIRON PSYCHOL 2010, 30(1):129-132. 
3. Xu C, Zhu G, Xue Q, Zhang S, Du G, Xi Y, Palinkas LA: Effect of the Antarctic environment on hormone levels and mood of Chinese expeditioners. Int J Circumpolar Health 2003, 62(3):255-267.

4. Kjærgaard A, Leon GR, Fink BA: Personal challenges, communication processes, and team effectiveness in military special patrol teams operating in a polar environment. ENVIRON BEHAV 2015, 47(6):644-666.

5. Pedlar CR, Lane AM, Lloyd JC, Dawson J, Emegbo S, Whyte GP, Stanley N: Sleep profiles and mood states during an expedition to the South Pole. Wilderness Environ Med 2007, 18(2):127-132.

6. Lugg DJ: Behavioral health in Antarctica: implications for long-duration space missions. Aviat Space Environ Med 2005, 76(6 Suppl):B74-B77.

7. Palinkas LA, Johnson JC, Boster JS, Rakusa-Suszczewski S, Klopov VP, Fu XQ, Sachdeva U: Cross-cultural differences in psychosocial adaptation to isolated and confined environments. Aviat Space Environ Med 2004, 75(11):973-980.

8. Suedfeld P, Steel GD: The environmental psychology of capsule habitats. ANNU REV PSYCHOL 2000, 51:227-253.

9. Hawkes C, Norris K, Ayton J, Paton D: Mood fluctuation in Antarctic expeditioners: does one size fit all? POLAR REC 2019, 55(2):93-101.

10. Kroenke K, Spitzer RL, Williams JB: The PHQ-9: validity of a brief depression severity measure. J GEN INTERN MED 2001, 16(9):606-613.

11. Spitzer RL, Kroenke K, Williams JB, Lowe B: A brief measure for assessing generalized anxiety disorder: the GAD7. Arch Intern Med 2006, 166(10):1092-1097.

12. Kroenke K, Spitzer RL, Williams JB, Monahan PO, Lowe B: Anxiety disorders in primary care: prevalence, impairment, comorbidity, and detection. ANN INTERN MED 2007, 146(5):317-325.

13. Buysse DJ, Reynolds CR, Monk TH, Berman SR, Kupfer DJ: The Pittsburgh Sleep Quality Index: a new instrument for psychiatric practice and research. Psychiatry Res 1989, 28(2):193-213.

14. Jihua Xiao FX: Study on validity and reliability of Coping Style Questionnaire. Chinese mental health journal 1996(04):164-168.

15. Moraes MM, Bruzzi RS, Martins Y, Mendes TT, Maluf CB, Ladeira R, Nunez-Espinosa C, Soares DD, Wanner SP, Arantes R: Hormonal, autonomic cardiac and mood states changes during an Antarctic expedition: From ship travel to camping in Snow Island. PHYSIOL BEHAV2020, 224:113069.

16. Mairesse O, MacDonald-Nethercott E, Neu D, Tellez HF, Dessy E, Neyt X, Meeusen R, Pattyn N: Preparing for Mars: human sleep and performance during a 13 month stay in Antarctica. SLEEP 2019, 42(1).

17. Booker JM, Hellekson CJ: Prevalence of seasonal affective disorder in Alaska. Am J Psychiatry 1992, 149(9):1176-1182.

18. Partonen T, Pandi-Perumal SR: Seasonal affective disorder: practice and research: Oxford University Press; 2010.

19. Drew EM, Hanson BL, Huo K: Seasonal affective disorder and engagement in physical activities among adults in Alaska. Int J Circumpolar Health 2021, 80(1):1906058.

20. Saarijarvi S, Lauerma H, Helenius H, Saarilehto S: Seasonal affective disorders among rural Finns and Lapps. Acta Psychiatr Scand 1999, 99(2):95-101.

21. Wang R, Liu Y, Xue D, Yao Y, Liu P, Helbich M: Cross-sectional associations between long-term exposure to particulate matter and depression in China: the mediating effects of sunlight, physical activity, and neighborly reciprocity. J AFFECT DISORDERS 2019, 249:8-14.

22. Kim SY, Bang M, Wee JH, Min C, Yoo DM, Han S, Kim S, Choi HG: Short-and long-term exposure to air pollution and lack of sunlight are associated with an increased risk of depression: A nested case-control study using 
meteorological data and national sample cohort data. SCI TOTAL ENVIRON 2021, 757:143960.

23. Wilkins $\mathrm{CH}$, Sheline YI, Roe CM, Birge SJ, Morris JC: Vitamin D deficiency is associated with low mood and worse cognitive performance in older adults. Am J Geriatr Psychiatry 2006, 14(12):1032-1040.

24. Parker GB, Brotchie H, Graham RK: Vitamin D and depression. J AFFECT DISORDERS 2017, 208:56-61.

25. Penders TM, Stanciu CN, Schoemann AM, Ninan PT, Bloch R, Saeed SA: Bright Light Therapy as Augmentation of Pharmacotherapy for Treatment of Depression: A Systematic Review and Meta-Analysis. Prim Care Companion CNS Disord 2016, 18(5).

26. Peng D: General Psychology. Beijing Normal University Press; 2019.

27. Adamczyk K: Voluntary and Involuntary Singlehood and Young Adults' Mental Health: an Investigation of Mediating Role of Romantic Loneliness. CURR PSYCHOL 2017, 36(4):888-904.

28. Greitemeyer T: Stereotypes of singles: are singles what we think? EUR J SOC PSYCHOL 2009, 39(3):368-383.

29. Poortman A, Liefbroer AC: Singles' relational attitudes in a time of individualization. SOC SCI RES 2010, 39(6):938-949.

30. Ta VP, Gesselman AN, Perry BL, Fisher HE, Garcia JR: Stress of singlehood: Marital status, domain-specific stress, and anxiety in a national US sample. J SOC CLIN PSYCHOL 2017, 36(6):461-485.

31. Suls J, Martin R, David JP: Person-environment fit and its limits: Agreeableness, neuroticism, and emotional reactivity to interpersonal conflict. PERS SOC PSYCHOL B 1998, 24(1):88-98.

32. Lakuta P: Personality Trait Interactions in Risk for and Protection against Social Anxiety Symptoms. J PSYCHOL 2019, 153(6):599-614.

33. NICOLAS M, THULLIER-LESTIENNE F, BOUQUET C, GARDETTE B, GORTAN C, JOULIA F, BONNON M, RICHALET JP, THERME P, ABRAINI JH: AN ANXIETY, PERSONALITY AND ALTITUDE SYMPTOMATOLOGY STUDY DURING A 31-DAY PERIOD OF HYPOXIA IN A HYPOBARIC CHAMBER (EXPERIMENT 'EVEREST-COMEX 1997'). J ENVIRON PSYCHOL 1999, 19(4):407-414.

34. Kocevska D, Lysen TS, Dotinga A, Koopman-Verhoeff ME, Luijk M, Antypa N, Biermasz NR, Blokstra A, Brug J, Burk WJ et al: Sleep characteristics across the lifespan in 1.1 million people from the Netherlands, United Kingdom and United States: a systematic review and meta-analysis. Nat Hum Behav 2021, 5(1):113-122.

35. Grandner MA: Sleep, Health, and Society. Sleep Med Clin 2020, 15(2):319-340.

36. Grandner MA, Jackson NJ, Izci-Balserak B, Gallagher RA, Murray-Bachmann R, Williams NJ, Patel NP, Jean-Louis G: Social and Behavioral Determinants of Perceived Insufficient Sleep. FRONT NEUROL 2015, 6:112.

37. Sutin AR, Gamaldo AA, Stephan Y, Strickhouser JE, Terracciano A: Personality Traits and the Subjective and Objective Experience of Sleep. INT J BEHAV MED 2020, 27(4):481-485.

\section{Figures}





Figure 1

PHQ-9, GAD-7 and PSQI score distribution 


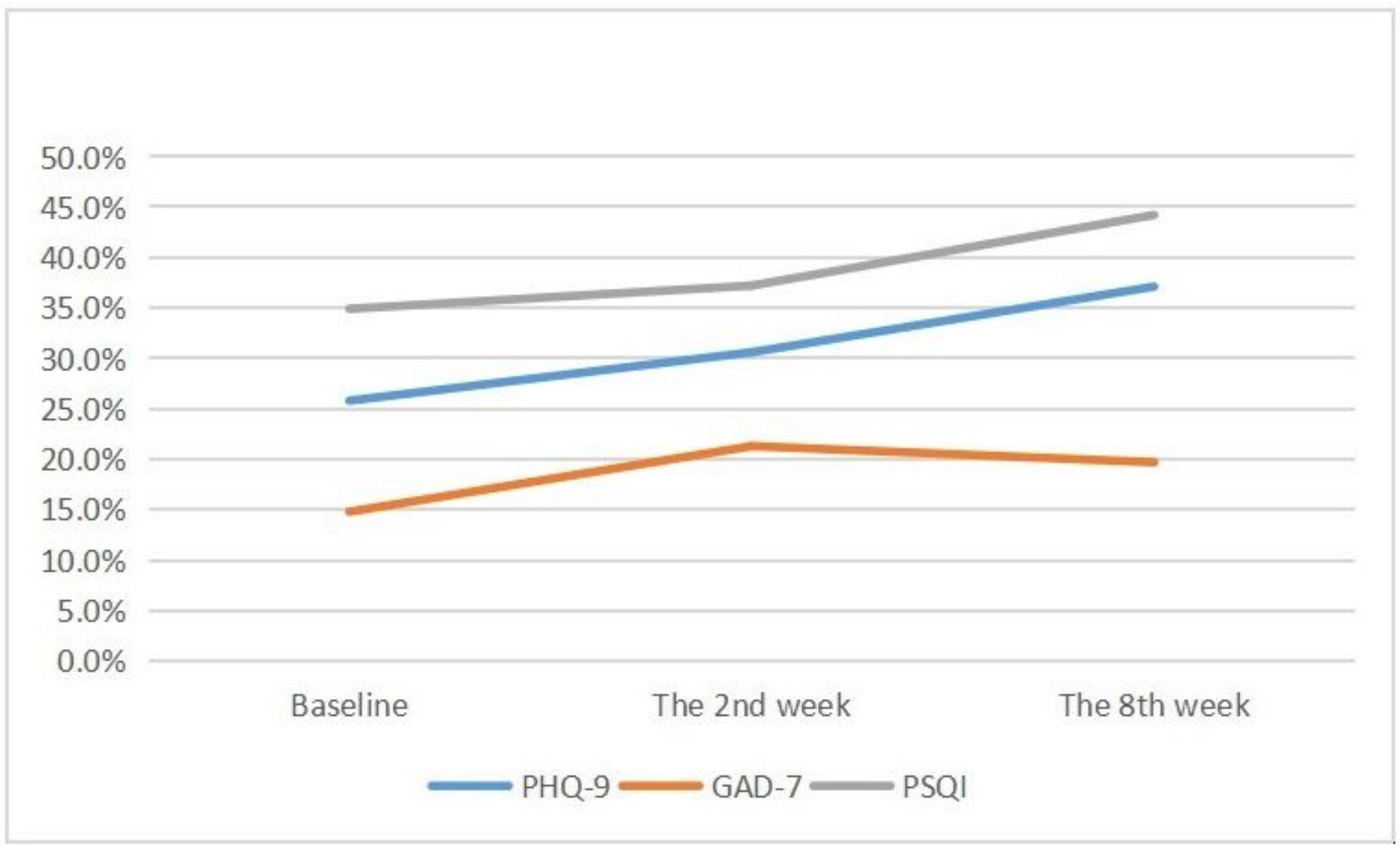

\section{Figure 2}

the different symptomatic groups of PHQ-9, GAD-7 and PSQI 